\title{
Misconduct in Financial Services: Differences across Organizations
}

\section{Citation}

Brown, Jennifer, and Dylan Minor. "Misconduct in Financial Services: Differences across

Organizations." Harvard Business School Working Paper, No. 16-022, August 2015

\section{Permanent link}

http://nrs.harvard.edu/urn-3:HUL.InstRepos:21150405

\section{Terms of Use}

This article was downloaded from Harvard University's DASH repository, and is made available under the terms and conditions applicable to Other Posted Material, as set forth at http:// nrs.harvard.edu/urn-3:HUL.InstRepos:dash.current.terms-of-use\#LAA

\section{Share Your Story}

The Harvard community has made this article openly available.

Please share how this access benefits you. Submit a story.

Accessibility 


\section{Misconduct in Financial Services: Differences across Organizations}

Jennifer Brown

Dylan Minor

Working Paper 16-022 


\title{
Misconduct in Financial Services: Differences across Organizations
}

\author{
Jennifer Brown \\ Northwestern University \\ Dylan Minor \\ Harvard Business School
}

Working Paper 16-022 


\title{
Misconduct in Financial Services: Differences across
}

\section{Organizations*}

\author{
Jennifer Brown \\ Northwestern University and NBER
}

\author{
Dylan Minor \\ Northwestern University
}

August 2015

\begin{abstract}
We examine misconduct in financial services. We propose a theory in which experts extract surplus based on the value of their firm's brand and their own skills. Using sales complaint data for insurance agents, we find that agents working exclusively for large branded firms are more likely to be the subject of justified sales complaints, relative to smaller independent experts, despite doing substantially less business. In addition, more experienced experts attract more complaints per year.
\end{abstract}

Keywords: Misconduct, expert services, asymmetric information, credence goods, insurance, ethics.

\footnotetext{
${ }^{*}$ We thank Luciano de Castro, Tim Feddersen, Craig Garthwaite, Tom Hubbard, Bruno Jullien, Mike Mazzeo, Nicola Persico, Mike Powell, Max Schanzenbach and seminar participants at Harvard Business School, UC-Berkeley, Northwestern University, Florida State University, NYU Stern, UT-Austin, 2012 NBER Law \& Economics Summer Institute, Center for Research in Economics and Strategy Conference, 2013 IIOC, and LMU Munich Workshop on Natural Experiments and Controlled Field Studies for helpful comments. Previous versions of this paper circulated under the title "Misconduct in Credence Good Markets." We are grateful to Eric Zhang and Tongtong Shi for excellent research assistance. We also thank individuals at the Texas Department of Insurance for their help in acquiring the data. Brown: jen-brown@kellogg.northwestern.edu Minor: d-minor@kellogg.northwestern.edu
} 
“... will people push the envelope and pitch lucrative and complicated products to clients even if they are not the simplest investments or the ones most directly aligned with the client's goals? Absolutely. Every day, in fact."

- Greg Smith, former executive at Goldman Sachs

New York Times Op-Ed (March 14, 2012)

Expert services firms often advise customers in markets with substantial asymmetric information problems; however, with these asymmetries comes the potential for expert misconduct. Specifically, while experts benefit from customers trusting their recommendations, these experts may also face incentives to provide misleading advice for their own gain. For example, investment or insurance advisors can recommend and sell products that offer customers fewer benefits, but provide themselves with greater revenue than the customers' ideal products.

Whereas previous research has explored how employee misconduct is influenced by individuals' gender, personality and moral differences (O'Fallon \& Butterfield 2005; McCabe, Ingram and Dato-on 2006; Greenberg 2002), the division of labor and goal setting within the firm (Ross 2013; Schweitzer, Ordóñez and Douma 2004) and firms' codes of ethics, human resource practices and culture (Grojean, Resick, Dickson and Smith 2004; Werbel and Balkin 2010; Ashforth and Anand 2003; Pierce and Snyder 2008), we present theoretical and empirical evidence about experts' propensity to engage in misconduct in different organizations when they face fixed prices. Specifically, we develop a formal model to consider differences in the incentives for malfeasance for experts working exclusively for large branded firms versus those working as independent sellers. Interest in these settings is motivated by their empirical prevalence - many financial services experts face fixed prices and commission rates while operating under one of the two prominent organizational structures. We also consider experts' professional experience, known to influence the propensity to engage in deceptive practices (Edelman and Larkin 2014).

The assumptions of the theory model reflect realistic features of expert services markets, particularly the market for financial advice and products. For example, in our model, when experts have identical underlying honesty, customers using exclusive agents fare better in expectation than customers using independent agents. In practice, experts working exclusively for large branded companies often enjoy more brand equity, offer additional services and support, and may be more 
heavily monitored by supervisors. Experts who provide larger expected consumer benefits may not be able to extract this surplus directly; instead, they may extract surplus through greater misconduct. The model provides similar intuition for understanding the role of expert experience. When experts' are equally honest, customers using more experienced experts may enjoy higher expected payoffs because these experts are less prone to mistakes. However, in equilibrium, some experienced experts may try to appropriate these benefits through greater misconduct.

To assess the empirical relevance of the hypotheses derived from the theory framework, we present an analysis of data from the insurance industry and show evidence that misconduct rates vary with expert sellers' affiliations and experience. Consistent with the testable hypotheses of the formal model, exclusive agents selling life insurance and annuities face more justified complaints than independent agents, and the disparity is not explained by differences in market share. Moreover, more experienced agents have greater per year complaint rates than less experienced agents.

Although complaints are an imperfect measure of misconduct, data summarizing accusations investigated by a state insurance regulator offer us a window into actual misconduct. In general, studies of misconduct face a trade-off: direct observation of misconduct through field experiments is necessarily limited in scale, while administrative data on reported misconduct may suffer from selection biases. Our main data set from a state regulator includes cases that have been reported and investigated. We take advantage of the observation of both accusations and confirmed cases of misconduct and find that our main results are robust to reporting and selection biases.

By exploring the link between misconduct, organizations and experts' experience, our paper addresses issues at the core of managers' and policymakers' concerns about vulnerable consumers in financial and other expert services markets. Our results suggest that price-taking experts' incentives for malfeasance are nuanced and misconduct is not just a theoretical possibility - concerns about misconduct have empirical support. Moreover, our work suggest a dark side to brand equity in markets where sellers cannot extract additional surplus through the price.

While our work focuses on difference in misconduct across seller types, others studies have explored the prevalence of misconduct in the financial services market. Mullainathan, Noeth, and Schoar (2012) conduct a field audit study in a U.S. market and find that financial advisors often recommend self-serving products. Anagol, Cole, and Sarkar (2012) conduct an audit study of insur- 
ance sales agents in India and find similar results. Even financial experts themselves acknowledge the ethical quandary of their field. In Cooper and Frank (2005), a survey of insurance agents finds that agents consistently identify ethical issues relating to the conflicts between customer benefits and opportunities for personal financial gain. We contribute to the discussion of misconduct in these markets by providing a stylized model of misconduct that explains our observations in life insurance and annuities sales.

Our empirical work focuses on the life insurance and annuities market, but the findings may be of wider interest. Financial services are but one example of a market in which it is difficult for a customer to determine whether the product or service is the best match for his or her needs; for example, drivers rely on mechanics' expertise and patients rely on physicians' advice and treatment. As a result, an expert who both advises and receives revenue based on his advice faces conflicting incentives. High quality advice may improve the customer's payoff; yet, when taken by the customer, inappropriate advice may lead to higher expert revenue.

It is important to note that the information asymmetries in our theoretical and empirical settings cannot be fully resolved through reputation building. ${ }^{1}$ Indeed, in its extreme, the nature of these expert services markets means that misconduct is seldom observed; therefore, the signals required for reputation building on this dimension are not sufficiently informative (Mailath and Samuelson 2001). As a result, it is not possible to build a reputation explicitly for ethical behavior in settings in which consumers rarely observe true quality. ${ }^{2}$ Curiously, however, we still observe strong branding by firms in many expert services settings - for example, insurance companies, wirehouses, and hospital networks are often heavily advertised. These brands may build consumers' confidence in a product or seller; yet individual agents may exploit the value that consumers place on the large branded firms to extract surplus through misconduct. While branding and reputation solve informational asymmetry in many markets, in our proposed model, the correlation between strong branding and higher additional surplus leads to the prediction that experts from large, branded

\footnotetext{
${ }^{1}$ Here, we consider the reputation of the individual agent, not the organization by which he or she is employed. In contrast to the broad literature on unethical behavior at the organizational level (e.g., Robinson and Bennet 1995; O'Leary-Kelly, Griffin, and Glew 1996; Robinson and O'Leary-Kelly 1998), we contribute to the literature studying individual employees' misconduct (e.g., Kidder 2005). Consistent with the approach in Werbel and Balkin (2010), we limit our study to considering misconduct that aims to enrich the employee without intentionally causing harm to the firm or its workers (Charness, Masclet and Villeval 2013).

${ }^{2}$ In environments in which customers can readily observe product quality, customer reviews may resolve some information asymmetries (Kalra, Shi and Srinivasan 2003).
} 
firms are actually more likely to engage in misconduct. In that sense, our results provide an interesting counterpoint to the conventional view of brand- and reputation-building as mechanisms that encourage experts to act in the interest of their clients.

Much of the work studying experts facing relatively naive consumers allows experts to adjust both the quality and the price of their service (Pessendorfer and Wolinsky 2003; Sulzle and Wambach 2005; Alger and Salanie 2006; Emons 1997; Gennaioli, Shleifer and Vishny 2012). In contrast to these studies, we explore a market with price-taking experts. The literature has also considered the importance of customer heterogeneity (cf. Fong 2005; Feddersen and Gilligan 2001; Taylor 1995; Inderst and Ottaviani 2009) or environments in which the expert aims to maximize customers' payoffs (Lightle 2009). Dulleck and Kerschbamer (2006) present a model that unifies the extant theory literature and rationalizes many of the previous theoretical findings. Our work complements these studies by adapting a market-level model of price-taking experts to explore the role of customer heterogeneity.

Despite the challenges, several empirical studies have examined experts decisions about what quality to provide and what price to charge their relatively uninformed customers. Hubbard (1998, 2002) finds that independent automotive service shops are more likely to provide favorable automotive emissions tests, relative to chain shops with non-owner managers. Bennett et al. (2013) find that increased competition also leads to more lenient emissions testing. Levitt and Syverson (2008) find that real estate agents invest more effort and secure higher prices for their own properties, relative to their customers' homes. We build on these empirical papers by exploring another important industry setting in which, unlike with vehicle inspectors and real-estate agents, experts face rigid commission rates. Whereas we focus on life insurance sales, other examples of price-taking experts include physicians with limited scope to adjust prices for specific patients and experts facing formally regulated prices.

\section{A model of expert misconduct}

We develop a formal model of consumers and experts that allows us to focus on two dimensions of expert services markets. First, we aim to understand if and how market-level misconduct varies across two common types of organizations. To that end, we compare misconduct from experts 
who work exclusively for large companies and independent experts who form their own small firms. Second, we consider how misconduct varies across experts with different levels of professional experience.

\section{$1.1 \quad$ Model set-up}

Consider an interaction between an expert and a customer that can result in two outcomes: the expert can recommend either an appropriate or inappropriate product. For convenience, we use the index " $R$ " and " $W$ " as mnemonics for the "right" and "wrong" products, respectively. We assume that the expert knows which product is appropriate for the customer, but the customer does not. After the expert makes his product recommendation, the customer must chose to buy or not to buy. The timeline for the expert-customer interaction is sequential and depicted below.

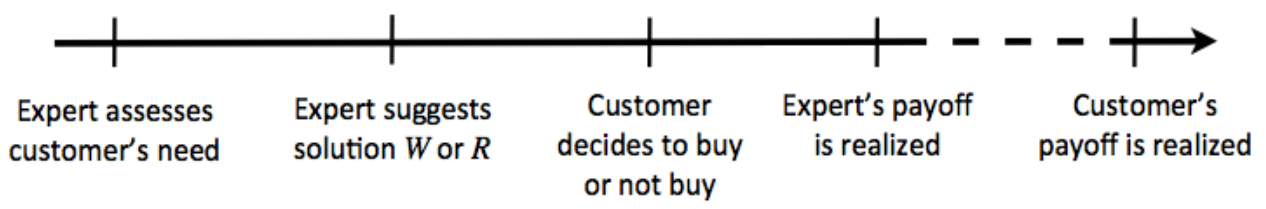

Suppose that payoff $\pi^{t}$ is a reduced form representation of the net payoff (i.e., gross revenue minus business expenses) of selling product $t \in\{R, W\}$, before any possible penalty for mis-selling to a customer (i.e., recommending $W$ ).

An expert's private cost of misconduct, penalty $k$, can be framed as his willingness to take advantage of a customer. Let $k$ be drawn from a commonly known distribution $F(\cdot) .{ }^{3}$ In equilibrium, there is some chance $b$ that the expert will face a customer who acts on his recommendation. Thus, taking $b$ as given, the probability that an expert suggests $W$ to a customer is

$$
\operatorname{Pr}\left(b \pi^{W}-k \geq b \pi^{R}\right)=F\left(b\left(\pi^{W}-\pi^{R}\right)\right) \equiv s(b)
$$

where $s(b)$ is the market-wide misconduct rate. To allow for the possibility of misconduct, we assume $F(0)=0$.

Now suppose that the customer earns a net payoff $V^{R}$ or $V^{W}$ from buying $R$ or $W$, respectively, where $V^{W}<0<V^{R}$. If the customer decides not to buy the product, then her payoff is her

\footnotetext{
${ }^{3}$ Tenbrunsel (1998) suggests that variation in individuals' ethical standards and financial needs leads to heterogeneous sensitivities to incentives for misconduct.
} 
normalized outside option, 0 . Hence, a customer will buy if

$$
s V^{W}+(1-s) V^{R} \geq 0 .
$$

We define a customer's payoff ratio as $\frac{V^{R}}{-V^{W}}\left(\right.$ recall that $\left.V^{W}<0\right)$, which is distributed according to $G(\cdot)$. Hence, the probability that a particular customer buys is

$$
\begin{aligned}
\operatorname{Pr}\left(s V^{W}+(1-s) V^{R} \geq 0\right) & =\operatorname{Pr}\left(\frac{V^{R}}{-V^{W}} \geq \frac{s}{(1-s)}\right) \\
& \Longrightarrow 1-G\left(\frac{s}{(1-s)}\right) \equiv b(s)
\end{aligned}
$$

where $b(s)$ is the market-wide buy rate.

To find the market equilibrium, we find the fixed point such that $s(b(s))=s$.

\subsection{Exclusive versus independent experts}

We next enrich the model by considering two different organizational structures: experts may work exclusively for large companies or as independent experts who form their own small firms. We index these experts with $m \in\{E, I\}$.

We assume that the price-taking experts face similar payoffs across the organizations $\left(\pi^{t}=\pi_{I}^{t}=\pi_{E}^{t}\right)$; however, payoffs to customers vary across firm types. Consistent with features of our empirical setting, customers gain additional payoff from working with exclusive experts affiliated with branded firms.

\section{Consumers' payoffs}

Differences between exclusive and independent agents, in terms of both branding and offerings, motivate the wedge between the consumers' payoffs from each type of organization. Brand can communicate to consumers both tangible and intangible attributes that differentiate goods (cf. Keller 1993; Keller and Lehmann 2006) and often reinforces positive features (Cobb-Walgren et al. 1995). Evidence that consumers pay a brand premium has been found across many product categories, and non-expert consumers are more likely to assign the premium than expert buyers (e.g. in financial markets (Billett, Jiang and Rego 2014) and for pharmacy and grocery products 
(Bronnenberg et al. 2014)). ${ }^{4}$

Consumers also may enjoy higher payoffs from the products available exclusively through branded sellers or from the breadth of services offered. ${ }^{5}$ Finally, consumers may believe that the severity of misconduct is less when experts' conduct is overseen by branch managers. ${ }^{6}$

In the formal model, to capture the wedge between customers' payoffs from different organization forms, we assume that $\frac{V_{E}^{R}}{-V_{E}^{W}}=\frac{V_{I}^{R}}{-V_{I}^{W}} \eta>\frac{V_{I}^{R}}{-V_{I}^{W}}$, where $\eta>1$.

\section{Consumers' buy rates}

Given the difference in consumers' payoffs between the organizations, the probability that a customer purchases from an exclusive expert is

$$
1-G_{E}\left(\frac{s}{\eta(1-s)}\right) \equiv b_{E}(s)
$$

and the probability that a customer purchases from an independent expert is ${ }^{7}$

$$
1-G_{I}\left(\frac{s}{(1-s)}\right) \equiv b_{I}(s)
$$

The market-wide equilibria is identified most easily through a graphical analysis. ${ }^{8}$ In Figure 1, we plot expert misconduct against customer buy rates. As expected, buy rates are decreasing functions of market-wide misconduct. Specifically, the solid downward sloping line, $b_{I}(s)$, plots the buy rate for customers of independent experts. The dotted line, $b_{E}(s)$, plots the buy rate for customers of exclusive experts. For all interior points, $b_{E}(s)$ lies above $b_{I}(s)$. Intuitively, for a given level of market-wide misconduct, customers will buy at a higher rate from exclusive experts because they receive a higher expected payoff. The upward sloping line, $s(b)^{-1}$, is the inverse of

\footnotetext{
${ }^{4}$ Although a full discussion of why brand premia persist over time is beyond the scope of the current paper, consumers purchase life insurance and annuities very infrequently and, therefore, have limited opportunities to accumulate knowledge about specific products or update their beliefs about firms' reputations.

${ }^{5}$ In the insurance market, exclusive agents may offer multi-product discounts, online account access, 1-800 telephone support, or multiple service locations. In principle, consumers in the insurance market could access and analyze the public complaints data and conclude that they should avoid particular agent types. It may also be the case that some consumers may not be as sensitive to branding and marketing. However, objective differences in branded firms' product offerings and services may provide sufficient incentive for consumers to still prefer the branded firms.

${ }^{6}$ To narrow our focus to the misconduct of individual financial advisors, we take insurance companies' reputations, prices, product offerings, and organizational structures as given. Although questions about reputation-building, pricing and personnel decisions at the firm level is beyond the scope of this paper, the interaction of firm choices and sales agents' behavior is an important area of future research.

${ }^{7}$ In this model, buy rates are not equivalent to market shares and, indeed, need not even be correlated.

${ }^{8}$ Formal proofs for all of the hypotheses are available in the Appendix.
} 
the market-wide misconduct rate. It slopes up because there is more market-wide misconduct when customers are more likely to purchase - more experts will find it profitable to take advantage of customers when customers are keen to buy. ${ }^{9}$ The intersections of these curves identify the equilibria and lead to Hypothesis 1.

Hypothesis 1 Exclusive experts are more likely to engage in misconduct than independent experts.

\subsection{Observable differences in experts' skill}

Consider a version of the model where, on occasion, experts inadvertently recommend the inappropriate product. Assume that experts vary in terms of ability and sometimes make harmful mistakes. ${ }^{10}$ In practice, regulators often view intentional and unintentional actions differently, where unintentional mistakes are not considered misconduct. Experts may also choose to recommend the inappropriate product, and these acts qualify as professional misconduct.

Let $h$ be the commonly known probability that an expert makes an error. Now, the probability that a particular customer buys is

$$
\begin{aligned}
\operatorname{Pr}\left[s V^{W}+(1-s)\left((1-h) V^{R}+h V^{W}\right) \geq 0\right] & =G_{h}\left(\frac{s+(1-s) h}{(1-s)(1-h)}\right) \\
& \Longrightarrow 1-G_{h}\left(\frac{s+(1-s) h}{(1-s)(1-h)}\right) \equiv b_{h}(s)
\end{aligned}
$$

We present a graphical analysis of the market-wide consequence of error-prone experts in Figure 2. Let $a$ be experts' error rate. The customer buy rate from experts who makes errors, presented as the downward-sloping solid line $b_{h=a}(s)$, lies above the customer buy rate from experts with an error rate greater than $a$, shown as the downward-sloping dotted line $b_{h>a}(s)$. All else equal, a customer is less likely to buy from a more error-prone expert. Consequently, in equilibrium, experts with lower error rates engage in more misconduct. We summarize this finding in our next hypothesis:

Hypothesis 2 More error-prone experts are less likely to engage in misconduct.

\footnotetext{
${ }^{9} \mathrm{~A}$ version of the model in which the penalty $k$ is a function of the misconduct rate $s$ yields similar results.

${ }^{10}$ For simplicity, we assume that experts cannot intend to recommend $W$ and mistakenly recommend $R$.
} 
Hypothesis 2 generates a corollary that is consistent with Edelman and Larkin's (2014) finding that more experienced professionals are more likely to engage in deceptive practices:

Corollary for Hypothesis 2 If the error rate is negatively correlated with experience, more experienced experts engage in more misconduct.

\section{Life insurance: Industry background}

Life insurance and annuities are complicated and multidimensional products, and it can be difficult for even sophisticated consumers to identify the appropriate policy for their needs. Insurers offer multiple "riders" and modifications that may be opaque to customers. For example, life insurance policies can be term, universal, whole, variable and variable universal, with terminal illness and disability waivers, long-term care provisions, and accidental death benefits. ${ }^{11}$ Customers may be sold inappropriate products but may never become aware of sellers' misconduct or mistakes. Moreover, insured customers and their beneficiaries may never learn whether there existed superior products in the market at the time of the purchases.

Although agents can suggest products for specific needs, they cannot adjust the prices faced by individual customers - this practice, called "rebating," is illegal in most jurisdictions. ${ }^{12}$ Instead, insurance agents can enhance their commissions by recommending inappropriate products to customers. Increased revenue can come from simply overselling the level of insurance or from selling products with a higher commission rates and lower benefits to buyers.

Commission rates vary significantly across and within product types (e.g. commissions on annuities range are 2 to $10 \%$ of the invested amount) and are rarely disclosed to customers. ${ }^{13}$ In general, the trade-off between the benefits to policyholders and the revenue for the sellers is substantial. For example, a so-called "bonus" annuity earns an additional interest rate in the first year that is negatively correlated with the commission rate.

\footnotetext{
${ }^{11}$ The National Association of Insurance Commissions publishes a buyers' guide that describes some of the product complexities (http://www.naic.org/documents/consumer_guide_life.pdf).

${ }^{12}$ Importantly, rebating is illegal in our data environment (Texas Insurance Code Chapter 1806, Section 53).

${ }^{13}$ Our commission rate estimates and discussion of monitoring within firms are based on personal communication with professional insurance agents working as both exclusive and independent sellers (see Section 2.1 for a description of these organizational structures).
} 


\subsection{Types of organizations}

Life insurance salespeople work primarily under the two different organizational structures: (1) sellers may work exclusively for large, branded insurance companies; or (2) sellers may work as independent experts who are not affiliated with any single insurance company.

\section{Exclusive agents}

Exclusive company agents are typically affiliated with only one insurance company and may market only approved products from that company. ${ }^{14}$ Firms' product lists are quite large in practice, and there is little concern that exclusive agents are too constrained in terms of available products. Insurance companies using exclusive agents may offer employment benefits packages and provide introductory training to inexperienced agents. In many cases, new agents receive guaranteed salaries that phase out as they build up "books" of business, typically over 12 to 24 months.

Multiple exclusive agents in a city or region often share the same office space and administrative staff. The hierarchy within these offices provides some level of supervision; for example, branch managers may oversee and approve large or complicated transactions.

Exclusive agents may earn 50 to $70 \%$ of the gross commission on their sales, depending on the type of insurance product. State Farm, Farmers Insurance, Allstate, Northwestern Mutual and New York Life are examples of firms using the exclusive agent model ${ }^{15}$; in general, these firms have well-known brand names. ${ }^{16}$

\section{Independent agents}

Independent agents are not affiliated with any single insurance company. While independent agents are not restricted to selling insurance from any particular company, they usually cannot market products from insurance companies that use exclusive agents. For example, independent agents cannot sell State Farm products. Independent agents are often "one agent shops," and their transactions are not overseen by managers or supervisors. Typically, independent agents are responsible for all of their expenses; however, they generally earn close to $100 \%$ of the gross

\footnotetext{
${ }^{14}$ These agents may also be authorized to market selected products from other companies through agreements between their primary company and other firms.

${ }^{15}$ For a list of firms by organizational structure, see A.M. Best Company's "Best's Key Rating Guide: Life/Health United State \& Canada." (2011).

${ }^{16}$ In 2010, State Farm, AXA, Allstate and Metropolitan Life appeared in Brandz's report on the top eight most valuable global brands in the insurance industry (report available online at http://c1547732.cdn.cloudfiles.rackspacecloud.com/BrandZ_Top100_2010.pdf).
} 
commissions on their sales.

For a given amount of business, after accounting for expenses, exclusive and independent agents earn roughly the same net commissions (Carson et al. 2007).

\subsection{Misconduct}

Both exclusive and independent agents can engage in various types of misconduct. In this paper, we focus on sales-level misconduct over which individual agents have control. Note that we are not considering misconduct by the insurance company, such as the unfair denial of claims.

Table 1 presents a summary of common categories of sales misconduct and complaints. Agents can pocket the policy premium and provide the customer with fraudulent insurance documents ("conversion"). Misleading advertising about policy features and the misrepresentation of insurancerelated information by an agent are also considered misconduct. Since the bulk of total commissions is earned in the first year of many life insurance policies, agents benefit from frequent policy changes. "Churning" describes when the agent induces a customer to (unnecessarily) cash out his existing policy in order to purchase a new policy from the same insurance company. "Twisting" is similar, but involves an unnecessary switch to a new policy from a different insurance company. Agents may offer unauthorized rewards - in the form of payments, favors, or other advantages - to induce a client to purchase a new policy or product ("improper inducement"). Agents may illegally bundle products by refusing to sell or renew a customer's policy unless the client agrees to purchase additional lines of coverage (e.g. life insurance tied to home or auto insurance). These examples of misconduct are not exhaustive: Unauthorized acts and other agent-level mishandling are other broad categories of agent-level misconduct.

Under U.S. law, insurance advisors are legally bound by "duty of care" and "duty of loyalty"; the former requires agents to recommend appropriate products and the latter restricts agents from enriching themselves at their clients' expense. Under these duties, an advisor holds greater liability in the case of an intentional mistake, relative to the case in which he or she inadvertently offered a client a sub-optimal product. Under the "best effort" rule, advisors who present themselves as more experienced may also be held to a higher standard. ${ }^{17}$

\footnotetext{
${ }^{17}$ For an illustrative legal case, see Bloor $v$. Falstaff Brewing Corp., 601. F.2d 614 (2d Cir. 1979).
} 


\subsection{Regulation}

A state-level regulator - in our empirical setting, the Texas Department of Insurance (TDI)oversees insurance-related business, including life insurance and annuities sales. Among its many responsibilities, the TDI is charged with enforcing state insurance laws and ensuring the fair treatment of consumers.

Complaints against insurance agents, agencies and companies can be filed with the TDI through a web-based form or by mail, fax, or email. ${ }^{18}$ The regulator then investigates and determines whether the agent or company violated the terms of the contract or broke state insurance law. If the complaint is deemed justified, the regulator can impose sanctions as outlined in the state insurance code.

State insurance code (Texas Insurance Code, Title 13, Chapter 4005, Section 101) considers intentionality. Indeed, the code states that only willful violations of insurance law will be disciplined. For example, regarding the misrepresentation of policy terms, the code states that it is "...an unfair or deceptive act or practice in the business of insurance to knowingly permit the making of, offer to make, or make a life insurance contract... other than as plainly expressed in the issued contract..." Thus, unintentional errors do not generally result in justified sales complaints, whereas intentional misrepresentation or mistreatment leads to justified complaints.

\section{Data}

Using multiple public sources, we compiled licensing, appointment, complaint, and market share data for the Texas insurance market. The data set covers the population of life insurance agents operating in the state in 2010 and reported incidents of sales misconduct from 1996 to 2010 .

\subsection{Agents}

The agent licensing data from the TDI include all individuals who were licensed to sell insurance in Texas in 2010. A unique agent identifier and the date on which the agent was first licensed in the state is available for 174,792 insurance agents.

\footnotetext{
${ }^{18}$ Our telephone conversations with representatives at the TDI suggest that most complaints come from individual customers.
} 
To identify the type of organization under which individual agents operate, we match firm and agent affiliation data from two sources. Firm-level data from A.M. Best identify insurance companies that use exclusive agents and those that sell through independent agents. ${ }^{19}$ TDI appointments data for the firms using exclusive agents list all agents who are allowed to sell products the firms' products. We match license holders to firms and, thus, characterize individual agents' affiliations. We identify 56,314 individuals who work as exclusive agents (32\% of licensees in the state) and assume that the balance work as independent agents.

Marketshare data from the TDI describe the in-state total premiums written for all insurance companies operating in Texas. Table 2 reports separately the premium and marketshare statistics for companies using exclusive and independent agents. While firms using independent agents hold the majority of the marketshare, premia per agent are approximately equal for exclusive and independent agents. ${ }^{20}$

\subsection{Complaints}

The TDI's public directory of complaints against insurance companies, agents and agencies describes more than 500,000 complaints filed between 1996 and 2010. The directory reports the date and nature of the complaint, the line of coverage, the name and license number of the subjects of the complaint, and whether the complaint was deemed "justified" or "unjustified" by the TDI.

Complaints vary considerably, from claims disputes to accusations of unfair cancellations. Many complaints, even those leveled at agents, relate to actions under the control of insurance companies (e.g., denial of claims and premium-related complaints). To focus on agents' misconduct in the sale of products about which typical consumers have particularly weak insight, we narrow our analysis to complaints about agents' sales practices. ${ }^{21}$ In total, we identify 5,406 accusations of sales misconduct leveled against 3,707 individuals present in our 2010 licensing data. In total, the TDI found that 1,962 sales complaints (approximately $36 \%$ of the total) were justified.

\footnotetext{
${ }^{19}$ In A.M. Best Company's "Best's Key Rating Guide: Life/Health United State \& Canada." (2011), this variable is labeled as a company's "marketing type."

${ }^{20}$ In their seminal work on property rights theory, Grossman and Hart (1986) apply their model to the insurance industry. They predict that firms using exclusive agents will hold the majority of marketshare in life insurance. Their predictions align with the insurance industry structure in the early 1980 s, when independent firms had only $12 \%$ of the life insurance market. Data from Texas suggest that these marketshares may have shifted in recent years.

${ }^{21}$ We exclude complaints relating to property and casualty products, medicare supplements and employment insurance sales, and those referred to other agencies for investigation. The TDI's records do not distinguish between complaints about life insurance and complaints about annuities.
} 
Figure 3 presents the distribution of total and justified complaints per agent by agent type. There are several things to note in the figure. First, exclusive agents face more total and more justified complaints than independent sellers - whereas 1,133 of the justified complaints are against exclusive agents, only 829 justified complaints are against independent agents. It does not appear that exclusive agents accumulate more complaints because they enjoy a higher volume of business. As noted above and in Table 2, firms using exclusive agents have much lower total marketshare by premiums written, relative to independent firms (17\% versus $83 \%)$. Exclusive agents receive roughly $35 \%$ more complaints, yet do only one-fifth of the business as measured by marketshare.

Second, complaints are rare events for both exclusive and independent agents. Only $2.75 \%$ of exclusive agents and $0.91 \%$ of independent agents are the subject of any complaint filed with the TDI; only $1.44 \%$ of exclusive agents and $0.53 \%$ of independent agents are named in a justified complaint. The infrequency with which complaints are filed highlights the difficulties that honest agents may face in building a reputation for ethical behavior in this setting.

Third, conditional on being the subject of any justified complaint, most agents receive only one complaint - $82 \%$ of exclusive agents and $84 \%$ of independent agents with any confirmed misconduct face only one complaint in the sample.

Figure 4 presents the distribution of complaints against exclusive and independent agents by agents' experience, as measured by the years between when agents were first licensed and when they received a justified complaint. We exclude agents with less than three years experience as of 2010, since their complaints may not yet have been processed by the TDI. The figure suggests that exclusive and independent agents do not face justified complaints only in their first years of service. Instead, relatively experienced agents - even those with more than 20 years in the industry — are still subject to justified complaints. Figure 5 also suggests that exclusive agents receive more complaints later in their careers, relative to independent agents $(p<0.01$ for a Kolmogorov-Smirnov test of equality).

These figures are suggestive - complaints seem to vary systematically with agent type and experience. We account for more factors in the regression analysis presented in the next section and explore alternative explanations in Section 5 . 


\section{Results}

Are exclusive agents more likely to have been the subject of a justified complaint, relative to independent agents? To address this question, we estimate the following equation:

$$
\operatorname{Pr}\left(\text { Complaint }_{i}=1\right)=\frac{1}{1+e^{-Q_{i}}}
$$

where Complaint Couals $_{i}$ when agent $i$ has been the subject of at least one justified complaint and where

$$
Q_{i}=\alpha \text { Exclusive }_{i}+\beta X_{i}
$$

where Exclusive $_{i}$ equals 1 when agent $i$ is an exclusive agent and 0 if the agent is independent, and matrix $X_{i}$ contains the control variables described below. Although the main thrust of our analysis concerns differences between exclusive and independent agents, the predictions from the model also speak to the role of agent experience.

Complaints against life insurance and annuities agents occur very infrequently in the Texas data-fewer than $2 \%$ of agents have been the subject of a justified complaint. Since typical econometric techniques may underestimate the probability of rare events, we employ a rare-events correction (King and Zeng 2001a, 2001b).

We include the following controls in $X_{i}$, summarized in Table 3:

Years since first licensed: As a proxy for agent experience, we calculate the years since an agent was first licensed to sell insurance in Texas. If agents were previously licensed in other states, then we will underestimate their professional experience; if agents instead allowed their licenses to lapse for interim periods, then we will overestimate their experience. ${ }^{22}$ On average, exclusive agents have been licensed longer than independent agents $(p<0.01)$, holding licenses for roughly 10.5 years and 7 years, respectively.

Out-of-state agent: All agents who market insurance in Texas must be licensed by the TDI; however, they may be physically located in another state. We use the address on agents' licenses to determine residency and include an indicator for agents outside of Texas. More independent agents have out-of-state business addresses, relative to exclusive agents $(p<0.01)$.

\footnotetext{
${ }^{22}$ We exclude the $1.5 \%$ of agents for whom licensing dates are not available.
} 
Professional designation: Insurance agents may seek certification from several professional organizations, which typically require members to complete course work, pass exams, and participate in continuing education. We match agents to member lists for 11 designations. ${ }^{23}$ In our empirical analysis, we include an indicator for agents with any professional designation. Very few sellers have professional credentials; however, slightly more exclusive agents hold an accreditation, relative to independent agents $(p<0.01)$.

Number of licenses: Although most agents are licensed to sell only one type of insurance, we include an indicator for agents licensed to sell other products (e.g. property and casualty insurance) along with life insurance and annuities. Independent agents are more likely to specialize in life insurance and annuities sales $(p<0.01)$.

Local population: Using a distance algorithm, we calculate the distance between the geographic centroids of all Texas ZIP codes and match ZIP codes to population data from the U.S. Census Bureau. We identify all ZIP codes within 25 miles of every agent's business address (for Texas residents) and aggregate ZIP code populations. Unfortunately, we are not able to map nonresident agents to any specific geographic region of Texas. For residents, there is little difference between the average local populations faced by exclusive and independent agents.

\subsection{Exclusive versus independent agents}

Table 4 reports estimation results from equation (1). To ease interpretation, we also report odds ratios. Each observation represents a unique agent. The regression reported in column 4.1 of Table 4 includes all agents in the data for whom information is available and includes controls for experience, professional credentials, residency, and licensing. The estimates suggest that exclusive agents are more likely to have received a justified complaint than independent agents $(p<0.01)$. Even before adjusting for the very unequal marketshares of firms using exclusive and independent agents - recall that, aggregating life insurance and annuities, exclusive agents do nearly fives times less business than independent agents - the odds of an exclusive agent being the subject of a justified complaint are roughly $73 \%$ higher than for an independent agent.

In column 4.2, we exclude agents with less than three years of experience as of 2010 , since these inexperienced agents may be still in their training period, may earn a guaranteed "training" salary,

\footnotetext{
${ }^{23}$ The designations are CFP, ChFC, CLU, CAP, CASL, CLF, FSS, LUTCF, MSFS, MSM, and REBC.
} 
or may not yet be responsible for generating their own sales. Excluding these agents does little to

change the coefficient of interest - the difference between exclusive and independent agents remains large $(p<0.01)$.

Both local and out-of-state agents can be licensed to market insurance products in Texas, and one might wonder if the observed difference is being driven by residency. Column 4.3 reports a regression that includes only agents who reside in Texas. The estimated coefficient on the indicator for exclusive agents is similar in magnitude to the other specifications.

Agents may face different potential volumes of business, depending on their location. Although agent-level data on the volume or value of transactions are not available, we proxy for these measures using ZIP code-level U.S. Census population data. In column 4.4, this measure of business volume is positive and very small in magnitude $(p<0.01)$. Its inclusion has little effect on the coefficient of interest.

\subsection{Years of experience}

Across the four specifications reported in Table 4, one additional year of agent experience is associated with a 4 to 7 percentage points increase in the odds of receiving a complaint. Of course, agents with more experience have had more opportunities to receive a complaint. In this section, we present evidence that longevity alone cannot explain the estimated relationship between experience and complaints.

In Table 5, we present results of a Tobit specification with a measure of misconduct normalized by agents' experience - complaints per licensed year - as the dependent variable. Column 5.1 of Table 5 excludes agents with less than three years of experience. Since we have only fifteen years of complaints data, we consider only agents with three to fifteen years of experience in column 5.2. In column 5.3, we further the restrict the sample to Texas resident agents only, and column 5.4 includes the measure of local population described above.

Across the four specifications in Table 5, exclusive agents are subject to more complaints per year of experience $(p<0.01)$ and complaints per year increases with years of experience $(p<$ 0.01). Without controlling for individual agents' marketshares, one additional year of experience is associated with an additional 0.01 to 0.02 complaints per year.

We expect our estimates to be a lower bound on the true effect of experience. The longer an 
agent has been in business, the greater the proportion of "bad apples" in his cohort that has been weeded out through disciplinary actions. Because we observe complaints only for agents licensed as of 2010, complaints against these bad agents are not included and this may bias the estimates towards zero. Client attrition may also attenuate estimates of the effect of agent experience. ${ }^{24}$

\section{$5 \quad$ Alternative explanations}

Although our empirical findings are consistent with the simple model of price-taking experts presented in Section 1, we also consider the following alternative explanations: agent sorting between firm types, consumer heterogeneity, and differences in firms' "deep pockets" and reporting rates.

\subsection{Agent sorting}

One might ask: Do firms using exclusive agents systematically hire less honest agents? This seems unlikely. Firms using exclusive agents typically have established screening processes for new salespeople (e.g. applications, background checks, and interviews), whereas independent agents establish their own practices and are not subject to this initial screening. Moreover, given the screening process at the large branded firms, dishonest exclusive agents who are fired from one firm are unlikely to gain employment at another firm using exclusive agents. Instead, they can move into independent sales. Thus, the pool of independent agents may include former exclusive agents who were terminated due to misconduct.

It is also unlikely that the disparity in misconduct rates is driven by honest exclusive agents transitioning to become independent operators after accumulating industry experience, leaving more dishonest agents in the pool of exclusive agents. Although we cannot see these career transitions directly, this movement would result in relatively young exclusive agents and relatively old

\footnotetext{
${ }^{24}$ The following example illustrates this potential. Suppose that there is no client attrition and an agent acquires 10 clients each year so that, in ten years, a new agent acquires 100 clients. If the chance of receiving a complaint is $1 \%$ per client per year, then an agent with ten years of experience (in expectation) receives one complaint. In an agent's twentieth year, he has 200 clients and expects two complaints. Thus, without attrition, the number of complaints per year does not depend on experience. Now consider the role of client attrition. Over the past ten years, an agent with twenty years of experience acquires the same number of clients as an agent with only ten years of experience. However, due to attrition, the number of clients that he retains from his first ten years is now less than the number of clients from the more recent decade. Thus, assuming that the chance of a complaint is still $1 \%$ per client per year, we expect the ratio of complaints per year of the agent with twenty years of experience to be less than the ratio of the agent with ten years of experience. Thus, we underestimate the true effect of experience on complaints.
} 
independent experts. However, on average, exclusive agents have been licensed significantly longer than independent agents (Table $3 ; p<0.01$ ).

Evidence also suggests that the disparity is not driven by out-of-state agents whose misconduct might be difficult to detect because of distance. There are significantly more out-of-state independent sellers, relative to exclusive agents (Table 3; $p<0.01$ ). Moreover, the regression presented in column 4.3 excludes out-of-state agents and still estimates a large difference between agent types $(p<0.01)$.

Are bad agents being detected and fired by the firms using exclusive agents? Although not directly observable in the data, this sorting would work against our predicted effect. That is, we would expect higher complaint rates for independent agents if these firms included dishonest (former) exclusive agents.

Agents might also sort geographically - one might wonder if differences in agents' behavior result from differences in local competitive landscapes. An average Texas ZIP code contains 31 independent agents (standard deviation of 52) and 19 exclusive agents (standard deviation of 34), and approximately $84 \%$ of ZIP codes in Texas contain at least one of each agent type. Given that both agents and customers are likely to transact across ZIP codes, we construct another measure of local competition. We identify all ZIP codes within 25-miles of an agent's business address and count the total number of agents within that radius. Overall, exclusive and independent agents face similar volume and types of competitors: for both independent and exclusive agents, approximately $38 \%$ of agents within a 25 -mile radius are exclusive and $62 \%$ are independent.

\subsection{Customer heterogeneity}

In this section, we explore the consequences of heterogeneity in the population of buyers. Using both formal theory and empirical evidence, we argue that the matching of particularly savvy customers to independent agents (or vice versa) cannot fully rationalize the difference in observed misconduct rates.

To consider the impact of savvy consumers on the market equilibrium, we introduce "connoisseur" consumers into the formal model in Section $1{ }^{25}$ Connoisseurs are defined as consumers who

\footnotetext{
${ }^{25}$ Adding connoisseurs is equivalent to introducing some exogenous probability that a consumer knows the appropriate product.
} 
are perfectly informed about the appropriateness of the recommended product and, therefore, only and always buy from an expert who recommends $R$. We assume that experts cannot distinguish a connoisseur from a regular customer-otherwise, experts would always suggest $R$ to those consumers and regular consumers would be unaffected. For simplicity, assume that agents' types are fixed.

Suppose that there is a mass $\alpha$ of connoisseurs in the market. Now, experts enjoy a higher (or lower) expected payoff for suggesting $R$ (or $W$ ). Consider the probability of misconduct in a market with connoisseurs:

$$
\operatorname{Pr}\left[(1-\alpha)\left(b \pi^{W}-k\right)-\alpha k \geq(1-\alpha) b \pi^{R}+\alpha \pi^{R}\right]=F\left((1-\alpha) b\left(\pi^{W}-\pi^{R}\right)-\alpha \pi^{R}\right) \equiv s_{\alpha}(b)
$$

As expected, holding the buy rate fixed, misconduct is decreasing in $\alpha$.

Now, the buy rate for non-connoisseur consumers is

$$
\operatorname{Pr}\left(s V^{W}+(1-s) V^{R} \geq 0\right)=1-G\left(\frac{s}{(1-s)}\right) \equiv b_{\alpha}(s)
$$

Figure 5 plots the market-wide misconduct and buy rate when we introduce some mass $\alpha$ of connoisseur consumers, and we can compare this market against one with no such customers (i.e., when $\alpha=0$ ). In this setting, it is the misconduct curve - the inverse of the market-wide supply $s_{\alpha}^{*}(b)$ - that changes. Intuitively, with the introduction of connoisseur consumers, the expected payoff to misconduct is reduced in two ways: first, experts face a greater chance of being caught when suggesting $W$; and, second, experts are more likely to be rewarded with a purchase when they suggest $R$. That is, the presence of connoisseur consumers provides both a stick and carrot to entice more experts towards appropriate recommendations. Graphically, the line representing the inverse of market-wide level of misconduct in the presence of connoisseur consumers $\left(s_{\alpha>0}(b)^{-1}\right)$ lies above the misconduct curve when connoisseurs are not in the market $\left(s_{\alpha=0}(b)^{-1}\right)$. The new equilibrium with connoisseur consumers is characterized by less overall misconduct and a higher market-wide buy rate. ${ }^{26}$ This yields the following hypothesis:

\section{Hypothesis 3 Increasing the mass of connoisseur consumers decreases misconduct.}

\footnotetext{
${ }^{26}$ If connoisseur consumers engage only with exclusive agents, then industry-level misconduct decreases relative to the baseline, but exclusive agents still engage in relatively more misconduct than independent agents.
} 
Although proprietary data on individual agents' clients are not available, we proxy for consumer awareness using demographic data for the populations near agents' business addresses. For this empirical exercise, we assume that employment in the finance, banking or insurance industry is correlated with knowledge of insurance needs and measure the proportion of the local population that is employed in the financial sector. We match ZIP codes within 25 miles of an agent's business address to employment statistics in the 2010 County Business Pattern data from the U.S. Census Bureau. $^{27}$

Using the same control variables as in Table 4, we augment equation 1 with the measure of the local population's employment in finance. ${ }^{28}$ The coefficient on employment in finance is positive in all specifications, but varies in terms of magnitude and statistical significance. Importantly, inclusion of the measure of consumer awareness has little impact on the main coefficient of interestexclusive agents are associated with more justified complaints than independent agents. We also consider consumers' education levels using the percentage of the nearby population who completed college and find similar results.

\subsection{Deep pockets and reporting rates}

One might be concerned that customers of branded companies are more likely to file a complaint due to the firms' perceived "deep pockets." In this section, we explore this possibility and argue that it cannot fully explain the observed differences between complaints against exclusive and independent agents.

If the cost of filing is very low, then almost every discovered abuse should be reported - indeed, even customers who fail to detect any misconduct should contact the regulator for a costless (to them) review of the transaction. ${ }^{29}$ However, if there exists some material cost of filing a complaint, then customers of exclusive experts will report suspected misconduct more often if they expect a higher payoff from a successful complaint, relative to the payoff from a complaint about an independent seller. In this case, even if exclusive and independent experts are equally ethical,

\footnotetext{
${ }^{27}$ To calculate total employment in the financial sector, we multiplied the mid-point of an employment size class with the number of establishments in that class.

${ }^{28}$ For brevity, since the coefficient estimates vary little from those reported in Table 4 , the full table of results is omitted here.

${ }^{29}$ Empirically, the reporting cost is quite low, but not zero. Customers can complete a form on the TDI website in a matter of minutes. Moreover, insurance policies must list contact information for filing a complaint.
} 
exclusive experts will face more complaints.

A simple comparison of conviction rates suggests that "deep pockets" cannot rationalize the observed difference in complaint rates. If exclusive and independent agents are equally (un)ethical and customers complain about exclusive agents at a higher rate, then the conviction rate - the ratio of justified complaints to total complaints - will be lower for exclusive agents. ${ }^{30}$ However, the observed conditional conviction rates are, in fact, quite similar: 0.38 for exclusive agents versus 0.40 for independent agents. Therefore, there is little evidence that different reporting rates explain the large differences in exclusive and independent justified sales complaints. Similarly, there is little support for the claim that independent agents are more skilled at avoiding detection.

Moreover, according to the TDI, insurance companies often work directly with unhappy customers to resolve issues and discourage them from contacting the regulator. ${ }^{31}$ Insurance companies using exclusive agents have a structure that is particularly well-suited to diverting complaints - in general, branch and regional managers, as well as telephone customer service agents, can adjust policies or payments in response to customers' claims. In contrast, customers of independent experts may have little recourse before contacting the regulator. As a result, we might expect observed complaint rates for exclusive agents to represent a lower bound on actual misconduct.

\section{Conclusion}

This paper studies how the level of misconduct in expert services markets with price-taking advisors varies across different organizations. We propose a formal model in which price-taking experts extract surplus through increased malfeasance. Using data from the insurance regulator in Texas, we find support for the model's hypotheses. Namely, exclusive experts working for large branded firms are more likely to be the subject of a complaint, relative to independent experts, and experts with more experience are the subject of more complaints per year. Disparities across types of organizations and experience levels are not readily explained by differences in market share.

Our research relates to the current discussion of the Dodd-Frank Wall Street Reform and Consumer Protection Act of 2010 and the conflict of interest rules proposed by the U.S. Department of Labor. Currently, regulations distinguish between two types of investment experts and hold them

\footnotetext{
${ }^{30} \mathrm{~A}$ formal analysis supporting this intuition is available from the authors.

${ }^{31}$ We learned this through telephone conversations with staff at the TDI.
} 
to different standards of conduct. Registered investment advisors are held to a "fiduciary standard" that requires them to disclose all conflicts and provide the client with the most appropriate recommendation. In contrast, investment brokers are held to a lower "suitability standard" that requires them to provide the client with a recommendation that is consistent with their needs, but not necessarily the most appropriate. According to SEC research, many customers are unaware of the differing standards and believe that both advisors operate under the higher standard of conduct. ${ }^{32}$

Our study can inform the policy debate. Brokers often work for large branded companies, whereas registered investment advisors are often independent. We find that experts working in large branded firms are already more likely to extract surplus through misconduct. Thus, holding these brokers to a lower standard may exacerbate consumer harm.

In the same report, the SEC suggests that investor education is needed. Our formal model highlights the potential benefits of increased consumer awareness - the presence of many informed customers can reduce market-wide misconduct.

Finally, if more experienced advisors are more likely to take advantage of customers, the standards of conduct could vary across experience levels; however, to our knowledge, this type of professional standard has not yet been explicitly discussed by the regulator.

\footnotetext{
${ }^{32}$ U.S. Securities and Exchange Commission. 2011. "Study on Investment Advisers and Broker-Dealers." Available online as of 20 September 2013: http://www.sec.gov/news/studies/2011/913studyfinal.pdf
} 


\section{References}

[1] Alger, I. and F. Salanie. 2006. "A Theory of Fraud and Overtreatment in Experts Markets." Journal of Economics \& Management Strategy, 15(5): 853-881.

[2] Anagol, S., S.Cole, and S. Sarkar. 2012. "Understanding the Incentives of Commissions Motivated Agents: Theory and Evidence from the Indian Life Insurance Market." Working paper.

[3] Ashforth, B.E. and V. Anand. 2003. "The normalization of corruption in organizations." In B. M. Staw and R.M. Kramer (Eds.), Research in organizational behavior, JAI Press (Stamford, $\mathrm{CT})$.

[4] Bennett, V. M., L. Pierce, J.A. Snyder and M.W. Toffel. 2013. "Customer-driven misconduct: How competition corrupts business practices." Management Science, 59(8): 1725-1742.

[5] Billett, M.T., Z. Jiang, and L.L. Rego. 2014. "Glamour brands and glamour stocks." Journal of Economic Behavior $\&$ Organization.

[6] Bronnenberg, B. J., J.P. Dubé, M. Gentzkow, and J.M. Shapiro. 2014. "Do Pharmacists Buy Bayer? Informed Shoppers and the Brand Premium". National Bureau of Economic Research No. w20295

[7] Carson, J., R. Dumm, and R. Hoyt. 2007. "Incentive Compensation and the Use of Contingent Commissions: The Case of Smaller Distribution Channel Members." The Journal of Insurance Regulation 25(4): 53-67.

[8] Charness, G., D. Masclet and M.C. Villeval. 2013. "The dark side of competition for status." Management Science, 60(1): 38-55.

[9] Cobb-Walgren, C.J., C.A. Ruble and N. Donthu. 1995. "Brand Equity, Brand Preference, and Purchase Intent." Journal of Advertising, 24(3): 25-40.

[10] Cooper, R., and G. Frank. 2005. "The Highly Troubled Ethical Environment of the Life Insurance Industry: Has It Changed Significantly from the Last Decade and If so, Why?" Journal of Business Ethics, 58(1): 149-157. 
[11] Dulleck, U. and R. Kerschbamer. 2006. "On Doctors, Mechanics, and Computer Specialists: The Economics of Credence Goods." Journal of Economic Literature, 47: 5-42.

[12] Edelman, B. and I. Larkin. 2014. "Social comparisons and deception across workplace hierarchies: Field and experimental evidence." Organization Science 26(1): 78-98.

[13] Emons, W. 1997. "Credence Goods and Fraudulent Experts." The RAND Journal of Economics, 28(1) Spring: 107-119.

[14] Feddersen, T. and T. Gilligan. 2001 "Saints and Markets: Activists and the Supply of Credence Goods." Journal of Economics \& Management Strategy, 10(1) Spring: 149-171.

[15] Fong, Y. 2005. "When Do Experts Cheat and Whom Do They Target?" The RAND Journal of Economics, 36(1): 113-130.

[16] Gennaioli, N., A. Shleifer, and R.W. Vishny. 2012. "Money Doctors." NBER Working Paper No. 18174 .

[17] Greenberg, J. 2002. "Who stole the money and when? Individual and situational determinants of employee theft." Organizational Behavior and Human Decision Processes 89: 985-1003.

[18] Grojean, M. W., Resick, C. J., Dickson, M. W. and D.B. Smith. 2004. "Leaders, values, and organizational climate: Examining leadership strategies for establishing an organizational climate regarding ethics." Journal of Business Ethics 55: 223-241.

[19] Grossman, S., and O. Hart. 1986. "The Costs and Benefits of Ownership: A Theory of Vertical and Lateral Integration." Journal of Political Economy, 94(4) August: 691-719.

[20] Hubbard, T.N. 1998. "An Empirical Examination of Moral Hazard in the Vehicle Inspection Market." RAND Journal of Economics, 29(2) Summer: 406-426.

[21] Hubbard, T.N. 2002. "How Do Consumers Motivate Experts? Reputational Incentives in an Auto Repair Market." Journal of Law and Economics, 45 October: 437-468.

[22] Inderst, R. and M. Ottaviani. 2009. "Misselling through Agents." American Economic Review, 99(3): 883-908. 
[23] Kalra, A., M. Shi, and K. Srinivasan. 2003. "Salesforce compensation scheme and consumer inferences." Management Science 49(5): 655-672.

[24] Keller, K.L. 1993. "Conceptualizing, measuring, and managing customer-based brand equity." The Journal of Marketing: 1-22.

[25] Keller, K. and D. Lehmann. 2006. "Brands and Branding: Research Findings and Future Priorities." Marketing Science, 25(6): 740-759.

[26] Kidder, D.L. 2005. "Is it 'who I am', 'what I can get away with', 'or what you've done to me'? A multi-theory examination of employee misconduct." Journal of Business Ethics 57: 389-398.

[27] King, G. and L. Zeng. 2001a. "Logistic Regression in Rare Events Data." Political Analysis, $9(2): 137-163$.

[28] King, G. and L. Zeng. 2001b. "Explaining Rare Events in International Relations." International Organization, 55(3) August: 693-715.

[29] Levitt, S.D. and C. Syverson. 2008 "Market Distortions When Agents Are Better Informed: The Value of Information in Real Estate Transactions." Review of Economics and Statistics, 90(4): 599-611.

[30] Lightle, J. 2009. "The Paternalistic Bias of Expert Advice." Florida State University working paper.

[31] Mailath, G.J., and L. Samuelson. 2001. "Who Wants a Good Reputation?" Review of Economic Studies, 68 (2) April: 415-441.

[32] McCabe, A. C., Ingram, R., and M.C. Dato-on. 2006. "The business of ethics and gender." Journal of Business Ethics 64: 101-116.

[33] Mullainathan, S., M. Noeth, and A. Schoar. 2012. "The Market for Financial Advice: An Audit Study." NBER Working Paper No. 17929.

[34] O'Fallon, M.J. and K.D. Butterfield. 2005. "A review of the empirical ethical decision making literature: 1996-2003." Journal of Business Ethics, 59: 375-413. 
[35] O’Leary-Kelly, A.M., R.W. Griffin, and D.J. Glew. 1996. "Organization-motivated aggression: A research framework." Academy of Management Review 21: 225-253.

[36] Pessendorfer, W. and A. Wolinsky. 2003. "Second Opinions and Price Competition: Inefficiency in the Market for Expert Advice." The Review of Economic Studies, 70(2): 417-437.

[37] Pierce, L. and J. Snyder. 2008. "Ethical spillovers in firms: Evidence from vehicle emissions testing." Management Science 54(11): 1891-1903.

[38] Robinson, S. L. and R.J. Bennet, R. J. 1995. "A typology of deviant workplace behaviors: A multidimensional scaling study." Academy of Management Journal 38: 555-572.

[39] Robinson, S. L. and A.M. O'Leary-Kelly. 1998. "Monkey see, monkey do: The influence of work groups on the antisocial behavior of employees." Academy of Management Journal 41: 658-672.

[40] Ross, D. G. 2013. "An Agency Theory of the Division of Managerial Labor." Organization Science 25(2): 494-508.

[41] Schweitzer, M. E., L. Ordóñez and B. Douma. 2004. "Goal setting as a motivator of unethical behavior." Academy of Management Journal 47(3): 422-432.

[42] Sulzle, K. and A. Wambach. 2005. "Insurance in a Market for Credence Goods." The Journal of Risk and Insurance, 72(1): 159-176.

[43] Taylor, C.R. 1995. "The Economics of Breakdowns, Checkups, and Cures" Journal of Political Economy, 103(1) February: 53-74.

[44] Tenbrunsel, A. E. 1998. "Misrepresentation and expectations of misrepresentation in an ethical dilemma: The role of incentives and temptation." Academy of Management Journal 41(3): $330-339$.

[45] Werbel, J. and D.B. Balkin. 2010. "Are human resource practices linked to employee misconduct? A rational choice perspective." Human Resource Management Review 20(4): 317-26. 


\section{Appendix: Proofs}

Hypothesis 1 Exclusive experts are more likely to engage in misconduct than independent experts. Proof. This proof formalizes the results in Figure 1. Recall that $F(\cdot)$ is the same for both firm types and that, since $\eta>1, G_{E}(\cdot)<G_{I}(\cdot)$ for all $s \in(0,1)$. For any expert type, $b(s)$ is strictly decreasing in $s$ : in a market without misconduct, customers always buy $(b(0)=1)$ and, when experts always engage in misconduct, customers never buy $(b(1)=0)$.

Define the inverse of the misconduct function as $q(\cdot) \equiv s(b)^{-1}$. Since $s(b)$ is strictly increasing and continuous, so too is $q(\cdot)$. In addition, if customers never buy, then experts never engage in misconduct $(q(0)=0)$ and if customers always buy, then experts engage in misconduct $(q(1)>0)$.

A unique, interior equilibrium follows from: (1) the continuity of $b(\cdot)$ and $q(\cdot) ;(2)$ the ordering of end point values, $b(0)=1>q(0)=0$ and $b(1)=0<q(1)$; and (3) the strict monotonicity of $b(\cdot)$ and $q(\cdot)$.

To compare organizations, recall that $G_{E}(\cdot)<G_{I}(\cdot)$ for all interior values of $s$. That is, for all interior points and for a given level of misconduct, exclusive experts face a higher buy rate than independent experts $\left(b_{E}^{*}>b_{I}^{*}\right)$. This implies that the misconduct rate of exclusive experts is higher than that of independent experts $\left(s_{E}^{*}\left(b^{*}\right)>s_{I}^{*}\left(b^{*}\right)\right)$ because $s(b)$ is strictly increasing.

Hypothesis 2 More error-prone experts are less likely to engage in misconduct.

Proof. This proof formalizes the results in Figure 2. Note that $G_{h}(\cdot)$ is increasing in the error rate $h$. Holding fixed the misconduct rate $s$, the buy rate $b_{h}(s)$ is decreasing in $h$ for $s<1$.

The misconduct rate is unaffected by the introduction of error-prone experts since

$$
\operatorname{Pr}\left(b \pi^{W}-k \geq(1-h) b \pi^{R}+h\left(b \pi^{W}-k\right)\right)=F\left(b\left(\pi^{W}-\pi^{R}\right)\right) \equiv s_{h}(b)=s(b)
$$

Following arguments presented for Hypothesis 1, equilibrium misconduct $s_{h}^{*}\left(b^{*}\right)$ is decreasing in the error rate $h$.

Hypothesis 3 Increasing the mass of connoisseur consumers decreases misconduct.

Proof. This proof formalizes the results in Figure 5. Let $\alpha$ describes the mass of connoisseur consumers in the market. Define the inverse of the market-wide misconduct function as $q_{\alpha}(\cdot) \equiv$ $s_{\alpha}(b)^{-1}$, and note that $q_{\alpha}(\cdot)$ is strictly increasing and continuous in $s$. 
The buy rate in the presence of connoisseur consumers $\left(b_{\alpha}(s)\right)$ is strictly decreasing in $s$ : if experts never engage in misconduct, then customers always buy $\left(b_{\alpha}(0)=1\right)$ and if experts always engage in misconduct, then customers never buy $\left(b_{\alpha}(1)=0\right)$.

Consider the condition under which experts would not engage in misconduct: $s_{\alpha}(b)=0$ requires that $(1-\alpha) b\left(\pi^{W}-\pi^{R}\right)-\alpha \pi^{R}=0$, since $F(0)=0$. This implies that $b>0$ and, therefore, when the market includes some connoisseur consumers, even some positive buy rate yields a market with no misconduct.

The inverse of the market-wide misconduct function with connoisseur consumers lies above the original misconduct function $q_{\alpha>0}(0)>q_{\alpha=0}(0)$ for all values of $b$. However, conditional on a given level of misconduct, the buy rate is unchanged by the presence of connoisseurs $\left(b_{\alpha>0}(s)=b_{\alpha=0}(s)\right)$. Therefore, in equilibrium, market-wide misconduct declines with the presence of more connoisseur consumers. 
Figure 1: Market-wide misconduct

Figure 2: Market-wide misconduct with

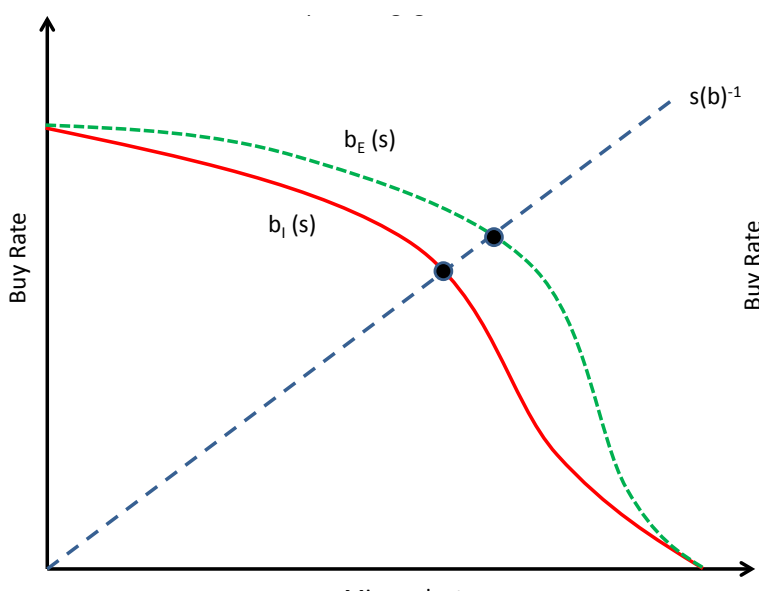

error-prone experts

Misconduct

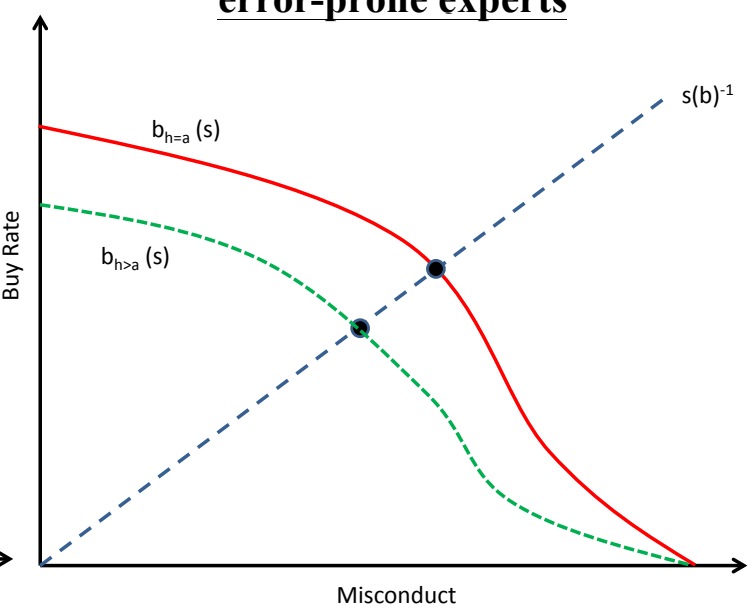

Figure 3: Complaints per agent by agent type

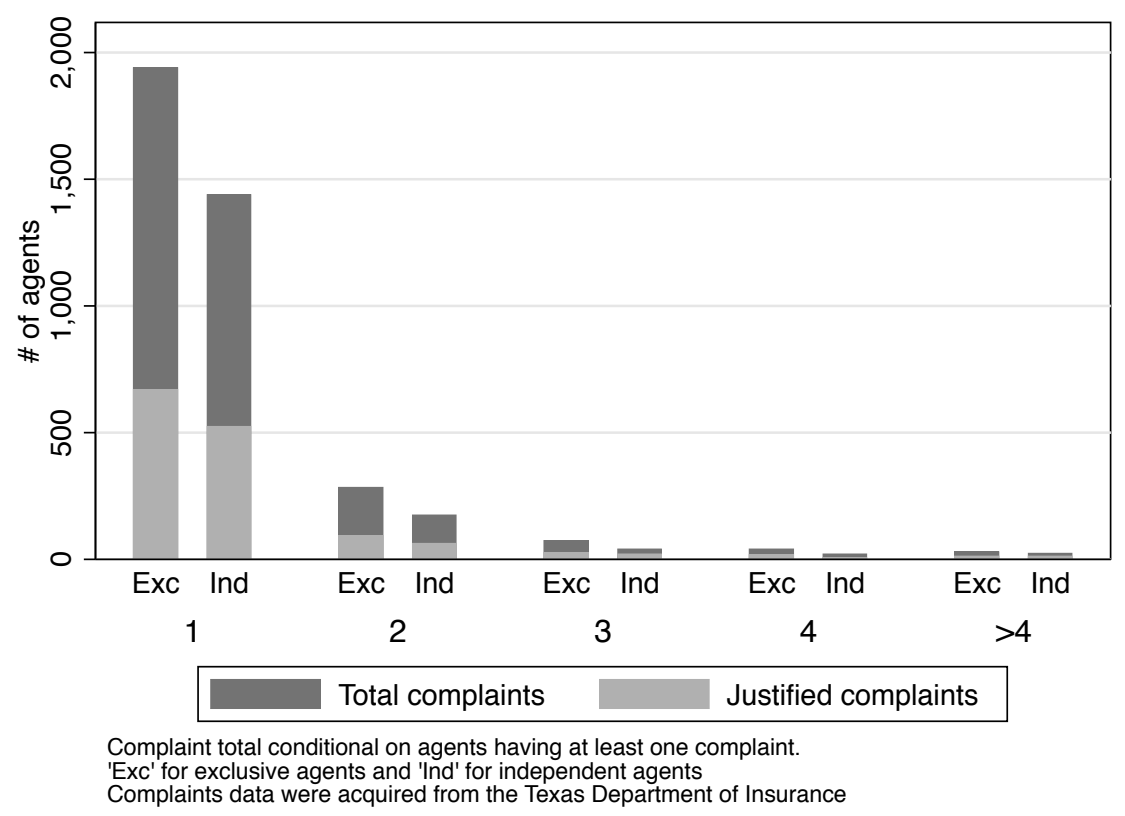


Figure 4: Distribution of experience of agents with justified complaints by agent type

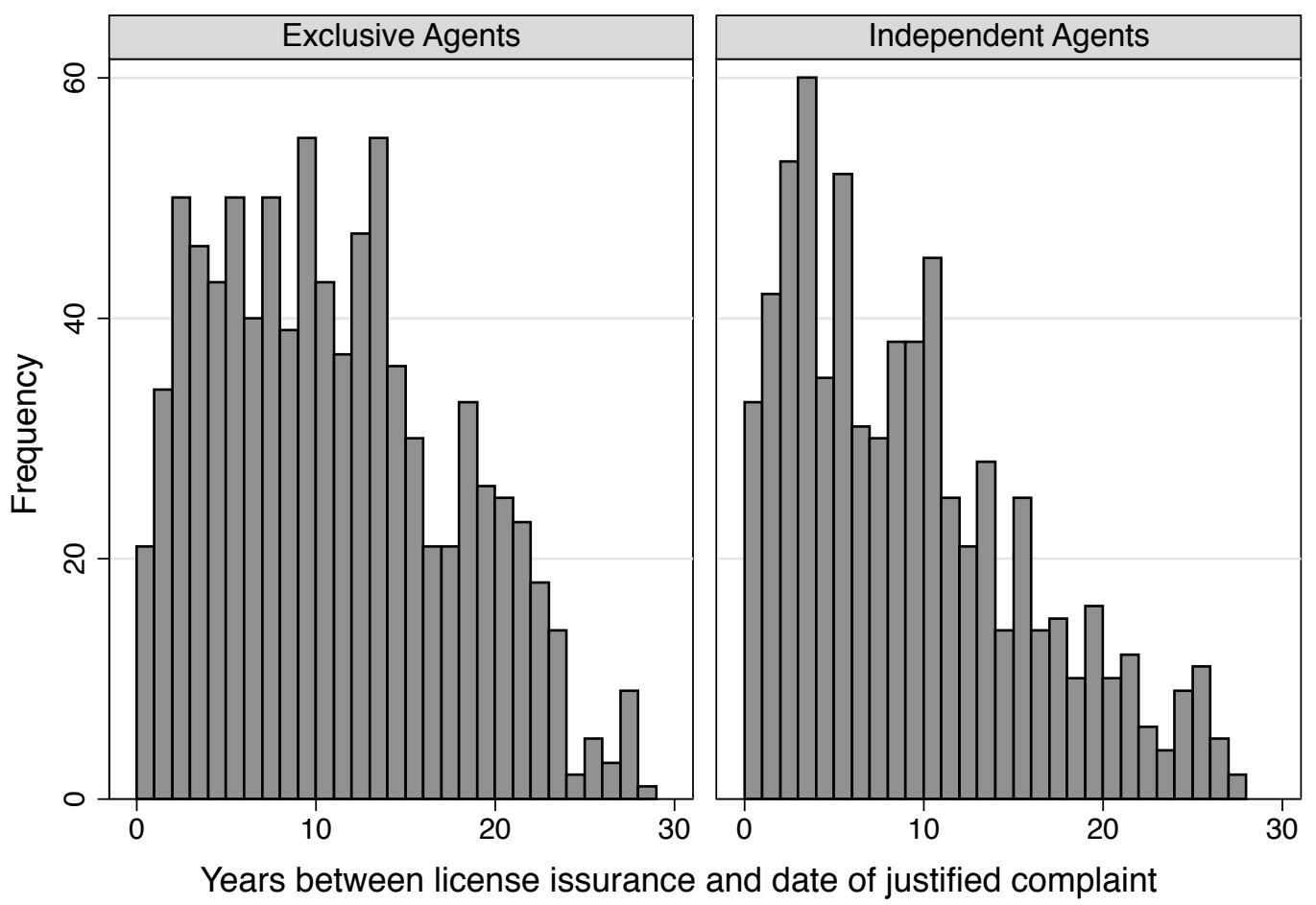

Figure 5: Market-wide misconduct with connoisseur consumers

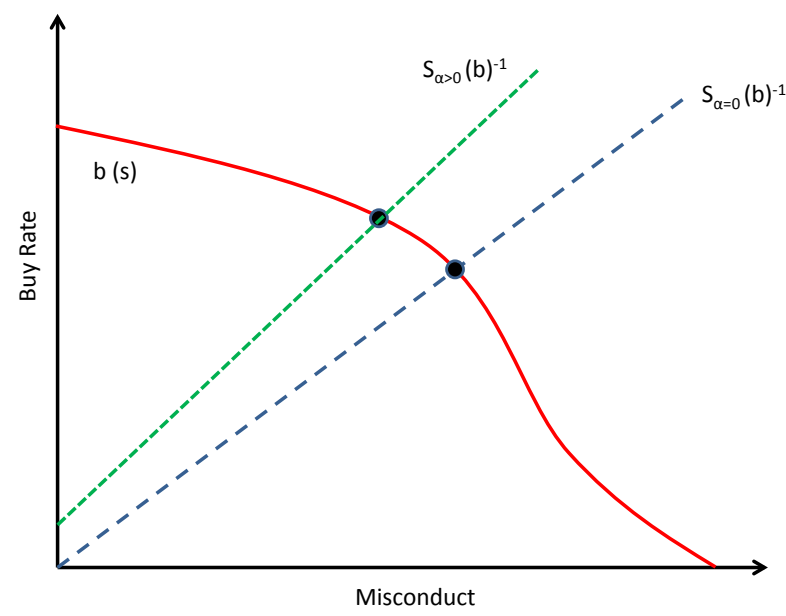


Table 1: Complaints against sales agents - Reasons, description and counts

Nature of Complaint Description

\begin{tabular}{|c|c|c|c|c|}
\hline Agent Mishandling & Improper customer sales or service practices. & 836 & 2421 & 3257 \\
\hline Churning & $\begin{array}{l}\text { Inducing a customer to use the cash value of an } \\
\text { existing policy to purchase a new policy from the } \\
\text { same insurance company, resulting in another } \\
\text { commission for the agent. }\end{array}$ & 66 & 39 & 105 \\
\hline Commissions & $\begin{array}{l}\text { Misrepresentation or unauthorized modification of the } \\
\text { agent's commission rate. }\end{array}$ & 73 & 190 & 263 \\
\hline Conversion & $\begin{array}{l}\text { Retaining a customer's premium and providing the } \\
\text { customer with fictitious insurance documents. }\end{array}$ & 629 & 39 & 668 \\
\hline Improper Inducements & $\begin{array}{l}\text { Offering pay, favors, advantage or other valuable } \\
\text { rewards (not offered in the insurance contract) as } \\
\text { inducement to enter into the insurance or annuities } \\
\text { contract. }\end{array}$ & 37 & 10 & 47 \\
\hline Misleading Advertising & $\begin{array}{l}\text { Making, publishing or disseminating public } \\
\text { announcements or advertisements containing untrue } \\
\text { or deceptive statements }\end{array}$ & 190 & 57 & 247 \\
\hline Misrepresentation & $\begin{array}{l}\text { Making untrue statement of facts, failing to state } \\
\text { critical facts, making misleading statements or } \\
\text { misstatements of the law, or failing to disclose a } \\
\text { matter required by law to be disclosed. }\end{array}$ & 967 & 1783 & 2750 \\
\hline Tie-In Sales & $\begin{array}{l}\text { Refusing to sell or renew a client's specific insurance } \\
\text { policy unless another policy is also purchased from } \\
\text { the agent. }\end{array}$ & 3 & 0 & 3 \\
\hline Twisting & $\begin{array}{l}\text { Inducing a customer to use the cash value of an } \\
\text { existing policy to purchase a new policy from a } \\
\text { different insurance company, resulting in another } \\
\text { commission for the agent. }\end{array}$ & 20 & 28 & 48 \\
\hline Unauthorized Acts & $\begin{array}{l}\text { Buying, modifying, or selling a customer's policy } \\
\text { without the customer's consent. }\end{array}$ & 943 & 135 & 1078 \\
\hline Total Complaints & & 3764 & 4702 & 8466 \\
\hline
\end{tabular}

Justified Unjustified Total

3257

05 
Table 2: Market share by product and firm type

\begin{tabular}{cc} 
Agent Type \\
Exclusive Independent \\
\hline
\end{tabular}

$\begin{array}{lccc}\text { Life Insurance Only } & \text { Total Premiums Written in millions \$ } & 2,618 & 6,598 \\ & \text { Average per Agent in thousands \$ } & 50,220 & 57,858 \\ & \text { Marketshare in \% } & 28 & 72 \\ \text { Annuities Only } & & 1,952 & 15,974 \\ & \text { Total Premiums Written in millions \$ } & 37,444 & 140,076 \\ & \text { Average per Agent in thousands \$ } & 11 & 89 \\ \text { Life Insurance and } & \text { Marketshare in \% } & & \\ \text { Annuities } & & 4,570 & 22,572 \\ & \text { Total Premiums Written in millions \$ } & 87,664 & 197,934 \\ & \text { Average per Agent in \$ } & 17 & 83\end{array}$

Note: Average premiums per agent were calculated using the total number of agents, by type, licensed to sell both life insurance and annuities in 2010.

Table 3: Agents in Texas by agent type - Summary Statistics

\begin{tabular}{lcccccc}
\cline { 2 - 3 } & \multicolumn{2}{c}{ Exclusive agents } & & \multicolumn{2}{c}{ Independent agents } \\
\cline { 2 - 3 } \cline { 5 - 6 } \cline { 5 - 6 } & Mean & Std. Dev & & Mean & Std. Dev \\
\hline Agent Years Licensed & 10.558 & 7.894 & & 6.976 & 6.841 \\
Texas Non-Resident (indicator) & 0.326 & 0.469 & & 0.477 & 0.499 \\
Professional Designation (indicator) & 0.017 & 0.131 & & 0.008 & 0.090 \\
One License Type Only (indicator) & 0.716 & 0.451 & & 0.822 & 0.382 \\
Local population (25 miles) in thousands & 11.912 & 9.009 & & 11.902 & 8.720 \\
& \multicolumn{2}{c}{$\mathrm{n}=52,131$} & & \multicolumn{2}{c}{$\mathrm{n}=114,038$} \\
\hline
\end{tabular}

Note: These data exclude agents for whom license dates were not available; * ZIP code population data are available only for agents who are residents of Texas. 
Table 4: Justified complaints

Dependent variable: Equals 1 if agent has received a justified complaint, 0 otherwise

\begin{tabular}{|c|c|c|c|c|c|c|c|c|}
\hline & All ag & ents & \multicolumn{2}{|c|}{$\begin{array}{c}4.2 \\
\text { All agents with } \\
>3 \text { years } \\
\text { experience }\end{array}$} & $\begin{array}{r}4 . \\
\text { Agents } \\
\text { Texas re }\end{array}$ & $\begin{array}{l}\text { with } \\
\text { idency }\end{array}$ & \multicolumn{2}{|c|}{$\begin{array}{c}4.4 \\
\text { Agents with Texas } \\
\text { residency }\end{array}$} \\
\hline & & $\begin{array}{l}\text { Odds } \\
\text { Ratio }\end{array}$ & & $\begin{array}{l}\text { Odds } \\
\text { Ratio }\end{array}$ & & $\begin{array}{l}\text { Odds } \\
\text { Ratio }\end{array}$ & & $\begin{array}{l}\text { Odds } \\
\text { Ratio }\end{array}$ \\
\hline Exclusive Agent & $\begin{array}{l}0.551^{* * *} \\
(0.059)\end{array}$ & 1.735 & $\begin{array}{l}0.536^{* * *} \\
(0.060)\end{array}$ & 1.709 & $\begin{array}{l}0.561 * * * \\
(0.062)\end{array}$ & 1.752 & $\begin{array}{l}0.551^{* * *} \\
(0.064)\end{array}$ & 1.735 \\
\hline Agent Years Licensed & $\begin{array}{l}0.089 * * * \\
(0.003)\end{array}$ & 1.093 & $\begin{array}{l}0.072 * * * \\
(0.003)\end{array}$ & 1.075 & $\begin{array}{l}0.069 * * * \\
(0.003)\end{array}$ & 1.071 & $\begin{array}{l}0.069 * * * \\
(0.004)\end{array}$ & 1.071 \\
\hline Texas Non-Resident & $\begin{array}{l}-1.918^{* * *} \\
(0.121)\end{array}$ & 0.147 & $\begin{array}{l}-1.883^{* * * *} \\
(0.124)\end{array}$ & 0.152 & & & & \\
\hline Professional Designation & $\begin{array}{l}-0.245 \\
(0.296)\end{array}$ & 0.783 & $\begin{array}{l}-0.236 \\
(0.296)\end{array}$ & 0.790 & $\begin{array}{l}-0.039 \\
(0.298)\end{array}$ & 0.962 & $\begin{array}{l}-0.123 \\
(0.326)\end{array}$ & 0.884 \\
\hline One License Type Only & $\begin{array}{l}0.727 * * * \\
(0.071)\end{array}$ & 2.069 & $\begin{array}{l}0.720 * * * \\
(0.071)\end{array}$ & 2.054 & $\begin{array}{l}0.742 * * * \\
(0.072)\end{array}$ & 2.100 & $\begin{array}{l}0.749 * * * \\
(0.075)\end{array}$ & 2.115 \\
\hline Local population ( $25 \mathrm{mi}$.) & & & & & & & $\begin{array}{l}-0.011^{* * *} \\
(0.003)\end{array}$ & 0.989 \\
\hline Constant & $\begin{array}{l}-6.353 * * * \\
(0.085)\end{array}$ & & $\begin{array}{l}-5.984 * * * \\
(0.091)\end{array}$ & & $\begin{array}{l}-5.972 * * * \\
(0.091)\end{array}$ & & $\begin{array}{l}-5.858 * * * \\
(0.101)\end{array}$ & \\
\hline
\end{tabular}

\# of observations

166,169

113,701

72,918

69,423

Note: Values in parentheses are robust standard errors. Logit coefficient and variance estimates are corrected using the rare-events correction of King and Zeng (2001a, 2001b). *** denotes $p<0.01$

Table 5 - Justified complaints per year

Dependent variable: Justified complaints per year of experience

\section{1 \\ 5.2 \\ 5.3 \\ 5.4}

Agents with $>3$ years experience

Exclusive Agent

$0.056^{* * *}$

(0.007)

Agent Years Licensed

$0.007 * * *$

$(0.000)$

Texas Non-Resident

$-0.189 * * *$

$(0.012)$

Professional Designation -0.039

$(0.033)$

One License Type Only $0.079 * * *$

$(0.008)$

Local population (25mi.)

Constant

$$
-0.801 * * *
$$

$(0.024)$

113,701
Agents with 3 to

15 years of experience

$\overline{0.073 * * *}$

$(0.014)$

$0.020 * * *$

$(0.002)$

$-0.305 * * *$

(0.024)

$-0.228$

(0.141)

$0.130 * * *$

(0.018)

$-1.293^{* * *}$

(0.059)
Texas resident agents with 3 to

15 years of experience

$\overline{0.060^{* * *}}$

(0.007)

$0.007 * * *$

(0.000)

$-0.011$

$(0.034)$

$0.082 * * *$

(0.008)

$-0.782 * * *$

(0.024)

72,918
\# of observations

84,628

$-0.019$

(0.037)

$0.084 * * *$

(0.008)

$-0.001 * * *$

(0.000)

$-0.782 * * *$

(0.025)
Texas resident agents with 3 to

15 years of experience

$0.059^{* * *}$

(0.007)

$0.007 * * *$

(0.000)

Note: Values in parentheses are robust standard errors. ${ }^{* * *}$ denotes $p<0.01$ 